\title{
Health Determinants of Asthma among Hispanic/ Latino Children Enrolled in the Michigan Migrant and Seasonal Head Start Programs
}

\author{
Nabila Farabi ${ }^{1}$ Sujin Song ${ }^{2}$ Elahé T. Crockett $^{3}$ \\ ${ }^{1}$ Department of Medicine, College of Human Medicine, Michigan \\ State University, East Lansing, Michigan, United States \\ 2 Department of Food and Nutrition, Hannam University, Daejeon, \\ South Korea \\ ${ }^{3}$ Department of Medicine, College of Human Medicine, Michigan \\ State University, East Lansing, Michigan, United States \\ ${ }^{4}$ Department of Food Science and Human Nutrition, Michigan State \\ University, East Lansing, Michigan, United States
}

\author{
Won O. Song ${ }^{4}$
}

J Child Sci 2019;9:e17-e23.

\author{
Address for correspondence Won O. Song, PhD, MPH, RD, \\ Department of Food Science and Human Nutrition, Michigan State \\ University, 135A FSHN building, 469 Wilson Road, East Lansing, \\ MI 48824, United States (e-mail: song@anr.msu.edu).
}

\begin{abstract}
Keywords

- asthma

- childhood obesity

- Hispanic/Latino children

- Migrant and Seasonal Head Start

Increasing prevalence of asthma in children in the United States is a major public health issue. Children in the Migrant and Seasonal Head Start (MSHS) program are one of the most vulnerable populations in the United States, with high rates of health disparities. We examined health determinants of asthma among Hispanic/Latino children enrolled in the Michigan MSHS programs. This study was a secondary data analysis based on the 2012 to 2013 ChildPlus dataset collected by Michigan Telamon Corporation. Sociodemographic and health information of 905 children aged 0 to 5 years was obtained from the dataset. Data were collected through interviews with parents by Telamon's specialists at each of the 18 Michigan MSHS centers. To determine children having asthma, health specialists at each center asked parents if their child/children had ever received asthma treatment. Weight status of children was categorized into nonoverweight/obese, overweight, and obese according to age- and sex-specific World Health Organization and Centers for Disease Control and Prevention growth chart standards. Multivariate logistic regression was used to identify asthma determinants. The overall prevalence of taking asthma treatment among Michigan MSHS children was 5.5\%. Obese children had a higher odds ratio (OR) of asthma compared with nonoverweight/obese children (OR: 2.52; 95\% confidence interval: 1.334.78). Children's age, health insurance status, and mothers' employment status were associated with asthma ( $p$-values $<0.05$ ). MSHS children are vulnerable to asthma, and their sociodemographic and obesity status are key determinants of having asthma. Identifying determinants of asthma might be helpful to design health policies and programs as well as implement health services for this population.
\end{abstract}

\section{Introduction}

Increasing prevalence of asthma, a chronic lung disease, is a major public health issue in children in the United States. ${ }^{1}$ Asthma causes inflammation and narrowing of the airway and is associated with increased risks of hay fever, respiratory allergies, eczema, skin allergies, sinusitis, food- or digestion-related allergies, fatigue, and struggle with emotional, behavioral, and cognitive health. ${ }^{2}$ In 2014 , the prevalence of asthma among US children aged less than 18 years received

November 1, 2018 accepted after revision March 22, 2019
DOI https://doi.org/ 10.1055/s-0039-1688764. ISSN 2474-5871.
Copyright $\odot 2019$ Georg Thieme Verlag License terms KG Stuttgart · New York
(1) (1) 
was $8.6 \%$ and among US children aged 0 to 4 years was $4.3 \%{ }^{3}$ In addition, asthma costs approximately US $\$ 56$ billion dollars annually, ${ }^{4}$ and most asthma hospitalizations occur between 3 and 5 years of age in the United States. ${ }^{5}$

Development of asthma in childhood is known to be linked to family history, allergies, infections, exposure to chemicals/ irritants, smoking, and air pollution. ${ }^{6-8}$ In addition to these risk factors, ethnic and socioeconomic characteristics have been reported as strong determinants of asthma. Previous studies have suggested that the prevalence of asthma is disproportionately higher among children from Hispanic/Latino backgrounds compared with non-Hispanic white children. ${ }^{5,9,10}$ In a study led by Crocker et al, ${ }^{11}$ Hispanic children significantly used fewer preventative medications and more short-acting medication for asthma management when compared with white children. This disparity in the risk of asthma also has also been observed in children from low-income families. ${ }^{9}$ Furthermore, overweight/obesity is also known as one of the important risk factors for asthma in childhood. $5,7,8,12-14$

Children from Migrant and Seasonal Farm Worker (MSFW) families are from racial/ethnic minority groups and have very low socioeconomic status, whose obesity rate is also higher when compared with children from similar income and racial/ ethnic groups. ${ }^{15}$ MSFWs and their children are further disadvantaged by high rates of food insecurity, living in adverse environments, and language and cultural barriers. ${ }^{15}$ They are also more exposed to agriculture fields and thus components of the field, such as pesticides, pollens, and other components, as a result of their parents' occupation as MSFWs. Therefore, children from MSFW families comprise a vulnerable population in the United States and thus may face very high rates of health disparities, particularly asthma. ${ }^{12}$

In a recent study, 3.4\% of MSFWs men were reported to have asthma and higher prevalence of respiratory symptoms such as wheezing, shortness of breath, and chest tightness with $11.4 \%, 14.0 \%$, and $16.8 \%$, respectively. ${ }^{16}$ Another study reported respiratory disease being the third most prevalent diseases among MSFWs in New York. ${ }^{17}$ However, little is known about the prevalence and determinants of asthma among children from MSFW families that can be used in the prevention and management of asthma. Database on health status of this group is very limited because MSFWs are hard to reach for research.

Although the number of MSFWs and their families is increasing in the United States, little research has been conducted on children of MSFW families and their health. MSFWs and their families are an essential component of the U.S. agricultural industry and thus improving their health status is important. As most asthma develops early in childhood $^{18}$ and as the health condition of children and adolescents is associated with their health condition during adulthood, ${ }^{19}$ it is necessary to determine the various factors related to asthma among MSFW's children for the early prevention of asthma and reduction of healthcare cost associated with asthma. Therefore, the aim of this study was to examine health determinants related to asthma treatment among MSFW's children enrolled in the Michigan Migrant and Seasonal Head Start (MSHS) programs.

\section{Methods}

\section{Participants}

This study was a secondary data analysis based on the ChildPlus dataset collected by Michigan Telamon Corporation during 2012 to 2013. Michigan Telamon Corporation operates 18 MSHS centers to provide federal preschool program and childcare 5 days a week that promotes the school readiness of children aged 0 to 5 years from MSFW families by enhancing their cognitive, social, and emotional development. ${ }^{20}$ In 2012, Michigan Telamon Corporation began collecting the ChildPlus dataset from their participants of MSHS programs at each Michigan MSHS center to meet the mandate of the federal government. The dataset includes information on sociodemographic characteristics of household and parents, anthropometric measurements of children, and disease treatment of children. The collected data are entered into a database software program named "ChildPlus" for administrative purposes.

Among 1,214 children who participated in the data collection, 309 children who had no valid information on sociodemographic characteristics of household and parents, anthropometric measurements, and asthma treatment were excluded. Therefore, a total of 905 children ( $0-5$ years) were included in the final data analyses. This study was exempted from the Institutional Review Board using the existing data, and the formal approval to use this dataset was obtained by the Michigan Telamon Corporation. Informed written consent was obtained from each parent to collect data. All subject-identifiable variables were removed from the dataset before the dataset was released to the research team. Routine collection of the data is a part of the program operation and report process.

\section{Data Collection}

Data on anthropometric measures and health status of children and sociodemographic backgrounds of parents and households were collected through interviews with parents by family service specialists and health specialists at each of the 18 Michigan MSHS centers. Due to the limited information on asthma diagnosis in the dataset used in this study, we used "asthma treatment" as a surrogate for quantifying children having asthma. For the outcome variable, health specialists at each center assessed asthma prevalence among children by asking parents if their child/children have ever received asthma treatment and documenting the response in enrollment forms as "yes" or "no." Exposure variables included (1) children's gender, age, health insurance, and weight status, (2) mother's age, education level, and employment status, and (3) household's total annual income, number of people in household, primary language at home, and participation of Special Supplemental Nutrition Program for Women, Infants, and Children (WIC) and Supplemental Nutrition Assistance Program (SNAP).

Children's weight and height were measured both at the beginning of the program and during a general health checkup by health specialists employed in the MSHS centers. Many children had multiple records for each of these measures and therefore we cleaned the data so that each child had one health measure for each. The health event date closest to the start date of enrollment was chosen for each child. For several children 
who did not have health measurements were taken during enrollment, the closest date to enrollment within 1 month before enrollment was used. Body mass index (BMI) was calculated using the following formula: weight $(\mathrm{kg}) /$ height squared $\left(\mathrm{m}^{2}\right)$. Weight status of children was categorized into nonoverweight/obese, overweight, and obese according to age- and sex-specific World Health Organization growth chart standards for children 0- to 23-month-old and Centers for Disease Control and Prevention growth chart standards for children older than 24 months. ${ }^{21}$

\section{Statistical Analyses}

All statistical analyses were conducted using SAS Version 9.4, 2014 (SAS Institute Inc., Cary, North Carolina, United States). To describe characteristics of children and their families, categorical variables were presented as frequencies and percentages, whereas continuous variables were presented as means and standard deviations. To test for the differences in characteristics between children who received asthma treatment and those who did not, the chi-square test was conducted for categorical variables and Student's $t$-test for continuous variables. Multivariate odds ratios (ORs) and 95\% confidence intervals (CIs) were obtained using the logistic regression after controlling for children's age, children's gender, mother's education level, and total annual household income. Any test of significance that was conducted was two-tailed, and a $p$-value of $<0.05$ was considered statistically significant.

\section{Results}

\section{Characteristics of Study Participants}

- Table 1 shows characteristics of Hispanic/Latino children enrolled in the Michigan MSHS programs. In this study population, the prevalence of asthma based on the information on receiving treatment for asthma was 5.5\%. The prevalence of overweight/obese was $34.8 \%$, and the percentage of children who did not have any health insurance was $15.4 \%$. The majority of families used only Spanish at home (93\%), and mothers of MSHS children showed low education level (78\% of mothers had education level of grade 9 or less). Half of the families had a total annual income of US\$20,000 or less. About $86 \%$ of the households participated in federal government nutrition programs such as WIC or SNAP.

\section{Differences in Characteristics by Asthma}

Compared with children in the nonasthma treatment group, children in the asthma group were more likely to be older, be obese, and have no health insurance. Mothers of children with asthma treatment were more likely to be unemployed compared with those of children without asthma treatment. Households of children with asthma treatment showed a higher number of people and a lower participation rate in federal government nutrition programs than households of children without asthma treatment ( - Table 2 ).

\section{Health Determinants of Asthma}

-Table 3 presents multivariate ORs of having asthma by health determinants. The age of children was positively
Table 1 Characteristics of 905 Hispanic/Latino children enrolled in the Michigan Migrant and Seasonal Head Start programs

\begin{tabular}{|c|c|c|}
\hline & \multicolumn{2}{|c|}{$\begin{array}{l}n(\%) \text { or } \\
\text { mean (SD) }\end{array}$} \\
\hline \multicolumn{3}{|l|}{ Children's characteristics } \\
\hline \multicolumn{3}{|l|}{ Gender } \\
\hline Female & 432 & $(47.7)$ \\
\hline Male & 473 & $(52.3)$ \\
\hline \multicolumn{3}{|l|}{ Age } \\
\hline Year & 2.7 & $(1.6)$ \\
\hline \multicolumn{3}{|l|}{ Weight status } \\
\hline Nonoverweight/obese & 590 & $(65.2)$ \\
\hline Overweight & 135 & $(14.9)$ \\
\hline Obese & 180 & $(19.9)$ \\
\hline \multicolumn{3}{|l|}{ Asthma treatment } \\
\hline Yes & 50 & $(5.5)$ \\
\hline No & 855 & $(94.5)$ \\
\hline \multicolumn{3}{|l|}{ Having health insurance } \\
\hline Yes & 766 & $(84.6)$ \\
\hline No & 139 & $(15.4)$ \\
\hline \multicolumn{3}{|l|}{ Mother's characteristics } \\
\hline \multicolumn{3}{|l|}{ Mother's age } \\
\hline Years & 28.0 & $(6.2)$ \\
\hline \multicolumn{3}{|l|}{ Mother's education level } \\
\hline Grade 9 or less & 709 & $(78.3)$ \\
\hline Grade 10 or more & 196 & $(21.7)$ \\
\hline \multicolumn{3}{|l|}{ Mother's employment status } \\
\hline Employed & 447 & $(49.4)$ \\
\hline Unemployed & 458 & $(50.6)$ \\
\hline \multicolumn{3}{|l|}{ Household's characteristics } \\
\hline \multicolumn{3}{|l|}{ Total annual income } \\
\hline US $\$ 15,000$ or less & 204 & $(22.5)$ \\
\hline US $\$ 15,000-$ US $\$ 20,000$ & 241 & $(26.6)$ \\
\hline US $\$ 20,000$ or more & 460 & $(50.8)$ \\
\hline \multicolumn{3}{|c|}{ Number of people in the household } \\
\hline Numbers & 4.7 & $(1.3)$ \\
\hline \multicolumn{3}{|l|}{ Primary language at home } \\
\hline Spanish & 839 & $(92.7)$ \\
\hline $\begin{array}{l}\text { Other } \\
\text { (including English) }\end{array}$ & 66 & $(7.3)$ \\
\hline \multicolumn{3}{|l|}{ WIC and SNAP participation } \\
\hline Both & 538 & $(59.5)$ \\
\hline $\begin{array}{l}\text { Either WIC } \\
\text { or SNAP }\end{array}$ & 243 & $(26.9)$ \\
\hline Neither & 124 & $(13.7)$ \\
\hline
\end{tabular}

Abbreviation: SD, standard deviation; SNAP, Supplemental Nutrition Assistance Program; WIC, Special Supplemental Nutrition Program for Women, Infants, and Children. 
Table 2 Characteristics by asthma treatment among 905 Hispanic/Latino children enrolled in the Michigan Migrant and Seasonal Head Start programs

\begin{tabular}{|c|c|c|c|c|c|}
\hline & \multicolumn{4}{|c|}{ Asthma treatment } & \\
\hline & \multicolumn{2}{|c|}{ No $(n=855)$} & \multicolumn{2}{|c|}{ Yes $(n=50)$} & \\
\hline & \multicolumn{4}{|c|}{$n(\%)$ or mean (SD) } & $p$-Value ${ }^{a}$ \\
\hline \multicolumn{6}{|l|}{ Children's characteristics } \\
\hline \multicolumn{6}{|l|}{ Gender } \\
\hline Female & 408 & $(47.7)$ & 24 & $(48.0)$ & 0.969 \\
\hline Male & 447 & $(52.3)$ & 26 & $(52.0)$ & \\
\hline \multicolumn{6}{|l|}{ Age } \\
\hline Years & 2.7 & $(1.6)$ & 3.7 & $(1.1)$ & $<0.001$ \\
\hline \multicolumn{6}{|l|}{ Weight status } \\
\hline Nonoverweight/obese & 563 & $(65.9)$ & 27 & $(54.0)$ & 0.014 \\
\hline Overweight & 130 & $(15.2)$ & 5 & $(10.0)$ & \\
\hline Obese & 162 & $(19.0)$ & 18 & $(36.0)$ & \\
\hline \multicolumn{6}{|l|}{ Having health insurance } \\
\hline Yes & 731 & $(94.5)$ & 35 & $(70.0)$ & 0.003 \\
\hline No & 124 & $(14.5)$ & 15 & $(30.0)$ & \\
\hline \multicolumn{6}{|l|}{ Mother's characteristics } \\
\hline \multicolumn{6}{|l|}{ Mother's age } \\
\hline Years & 28.0 & $(6.2)$ & 28.7 & $(5.5)$ & 0.421 \\
\hline \multicolumn{6}{|l|}{ Mother's education level } \\
\hline Grade 9 or less & 666 & $(77.9)$ & 43 & $(86.0)$ & 0.176 \\
\hline Grade 10 or more & 189 & $(22.1)$ & 7 & $(14.0)$ & \\
\hline \multicolumn{6}{|l|}{ Mother's employment status } \\
\hline Employed & 430 & $(50.3)$ & 17 & $(34.0)$ & 0.025 \\
\hline Unemployed & 425 & $(49.7)$ & 33 & $(66.0)$ & \\
\hline \multicolumn{6}{|l|}{ Household's characteristics } \\
\hline \multicolumn{6}{|l|}{ Total annual income } \\
\hline US $\$ 15,000$ or less & 196 & $(22.9)$ & 8 & $(16.0)$ & 0.517 \\
\hline US $\$ 15,000-$ US $\$ 20,000$ & 227 & $(26.6)$ & 14 & $(28.0)$ & \\
\hline US $\$ 20,000$ or more & 432 & $(50.5)$ & 28 & $(56.0)$ & \\
\hline \multicolumn{6}{|c|}{ Number of people in the household } \\
\hline Numbers & 4.7 & $(1.3)$ & 5.1 & $(1.3)$ & 0.051 \\
\hline \multicolumn{6}{|l|}{ Primary language at home } \\
\hline Spanish & 791 & $(92.5)$ & 48 & $(96.0)$ & 0.357 \\
\hline Other (including English) & 64 & $(7.5)$ & 2 & $(4.0)$ & \\
\hline \multicolumn{6}{|l|}{ WIC and SNAP participation } \\
\hline Both & 514 & $(60.1)$ & 24 & $(48.0)$ & 0.047 \\
\hline Either WIC or SNAP & 228 & $(26.7)$ & 15 & $(30.0)$ & \\
\hline Neither & 113 & $(13.2)$ & 11 & $(22.0)$ & \\
\hline
\end{tabular}

Abbreviations: SD, standard deviation; SNAP, Supplemental Nutrition Assistance Program; WIC, Special Supplemental Nutrition Program for Women, Infants, and Children.

${ }^{a} p$-Values were obtained using the chi-square test for categorical variables and using the Student $t$-test for continuous variables.

associated with asthma (OR: 1.43; 95\% CI: 1.18-1.76; $p<0.001)$. Children who were obese had an increased OR of asthma compared with nonoverweight/obese children (OR: 2.52; 95\% CI: 1.33-4.78; $p=0.005$ ). Children who had no health insurance had a higher risk of asthma than those who had health insurance (OR: 3.06; 95\% CI: 1.59-5.90; $p<0.001)$. Children whose mothers were unemployed had increased odds of asthma compared with those whose mothers were employed (OR: 2.12; 95\% CI: 1.16-3.89; $p=0.015$ ). 
Table 3 Multivariate ORs and 95\% Cls for taking asthma treatment by health determinants among 905 Hispanic/Latino children enrolled in the Michigan Migrant and Seasonal Head Start programs $^{a}$

\begin{tabular}{|c|c|c|c|}
\hline & ORs & $95 \% \mathrm{Cls}$ & p-Value \\
\hline \multicolumn{4}{|l|}{ Children's characteristics } \\
\hline \multicolumn{4}{|l|}{ Gender } \\
\hline Male & 1.00 & (Ref) & \\
\hline Female & 0.99 & $(0.55-1.76)$ & 0.963 \\
\hline \multicolumn{4}{|l|}{ Age } \\
\hline Years & 1.43 & $(1.18-1.76)$ & $<0.001$ \\
\hline \multicolumn{4}{|l|}{ Weight status } \\
\hline Nonoverweight/obese & 1.00 & (Ref) & \\
\hline Overweight & 0.72 & $(0.27-1.91)$ & 0.507 \\
\hline Obese & 2.52 & $(1.33-4.78)$ & 0.005 \\
\hline \multicolumn{4}{|l|}{ Having health insurance } \\
\hline Yes & 1.00 & (Ref) & \\
\hline No & 3.06 & $(1.59-5.90)$ & $<0.001$ \\
\hline \multicolumn{4}{|l|}{ Parent's characteristics } \\
\hline \multicolumn{4}{|l|}{ Mother's age } \\
\hline Years & 1.00 & $(0.96-1.05)$ & 0.908 \\
\hline \multicolumn{4}{|l|}{ Mother's education level } \\
\hline Grade 9 or less & 1.00 & (Ref) & \\
\hline Grade 10 or more & 0.63 & $(0.28-1.43)$ & 0.265 \\
\hline \multicolumn{4}{|c|}{ Mother's employment status } \\
\hline Employed & 1.00 & (Ref) & \\
\hline Unemployed & 2.12 & $(1.16-3.89)$ & 0.015 \\
\hline \multicolumn{4}{|l|}{ Household's characteristics } \\
\hline \multicolumn{4}{|l|}{ Total annual income } \\
\hline US $\$ 15,000$ or less & 1.00 & (Ref) & \\
\hline $\begin{array}{l}\text { US } \$ 15,000- \\
\text { US } \$ 20,000\end{array}$ & 1.37 & $(0.56-3.37)$ & 0.491 \\
\hline US $\$ 20,000$ or more & 1.22 & $(0.54-2.77)$ & 0.633 \\
\hline \multicolumn{4}{|c|}{ Number of people in the household } \\
\hline Numbers & 1.22 & $(0.98-1.52)$ & 0.083 \\
\hline \multicolumn{4}{|l|}{ Primary language at home } \\
\hline Spanish & 1.00 & (Ref) & \\
\hline $\begin{array}{l}\text { Other } \\
\text { (including English) }\end{array}$ & 0.72 & $(0.16-3.19)$ & 0.661 \\
\hline \multicolumn{4}{|c|}{ WIC and SNAP participation } \\
\hline Both & 1.00 & (Ref) & \\
\hline Either WIC or SNAP & 1.33 & $(0.68-2.60)$ & 0.409 \\
\hline Neither & 1.64 & $(0.77-3.51)$ & 0.202 \\
\hline
\end{tabular}

Abbreviations: Cls, confidence intervals; ORs, odds ratios; Ref, reference; SNAP, Supplemental Nutrition Assistance Program; WIC, Special Supplemental Nutrition Program for Women, Infants, and Children.

${ }^{\mathrm{a}} \mathrm{ORs}(95 \% \mathrm{Cls}$ ) and $p$-values were obtained from the logistic regression for all variables after adjustment for children's gender, children's age, mothers' education level, and total annual household income.

\section{Discussion}

This study presents the determinants of asthma among children enrolled in the Michigan MSHS Programs. These children are one of the most vulnerable groups in the United States and face very high rates of health disparities including asthma and obesity. However, there has been no information on the prevalence of asthma among this specific population. In this study, the risk of asthma in MSHS children was determined as the prevalence of taking asthma treatment due to the lack of comprehensive data on the health information of MSHS children. The prevalence of taking asthma treatment was $5.5 \%$. We also found that the key determinants related to asthma among Michigan MSHS children were obesity status of children and other factors such as children's age, children's health insurance status, and mothers' employment status.

The prevalence of asthma based on the information on receiving treatment for asthma among Michigan MSHS children in this study was higher than that of both general U.S. (4.3\%) and Hispanic (4\%) children of similar age. ${ }^{6}$ Although the comparison groups for the prevalence of asthma slightly differed in age by 1 year ( $0-5$ years vs. $0-4$ years), MSHS centers enroll children between the age of 2 weeks and 5 years, whose migrant parents have relocated within the last 24 months, and $54 \%$ of the children are less than 2 years. ${ }^{22}$ In addition, the survey question wording for determining asthma prevalence differed between the National Health Interview Survey (NHIS) 2014 and our study population. ${ }^{23}$ In our study, "asthma" was identified if the child had received treatment for asthma, whereas the NHIS identified asthma if the child was diagnosed or noted to have asthma by a physician or other health care providers. However, NHIS acknowledges that question types may vary between surveys ${ }^{24}$; thus, the two groups remain comparable. The prevalence of asthma among Michigan MSHS children was slightly lower than that of children of similar age, who were from families with income $100 \%$ below poverty level (5.9\%). ${ }^{3}$ However, the prevalence of asthma among children (0-4 years old) from families with income $100 \%$ below poverty level is the combined prevalence of asthma from all racial/ethnic backgrounds and may be overestimated. MSHS children also face higher exposure to asthma risk factors than those of children from low socioeconomic families. ${ }^{13}$ It might be explained by the complex interplay of unique health challenges faced by this community, such as their Hispanic/Latino ethnicity, low socioeconomic status, and poor living environments as a result of their parents' occupation as MSFWs.

The prevalence of obesity among MSHS children (19.9\%) is also higher than that of Hispanic children (15.6\%) and more than two times of the U.S. children (8.9\%) of similar age. ${ }^{25}$ The significant association between obesity and increased prevalence of asthma among MSHS children was one of the major findings in our study. Obesity has been found to be a risk factor for asthma in children as well as in adults. ${ }^{26-28}$ Excess body fat as seen in obese children creates a proinflammatory environment that makes it more favorable for asthma. ${ }^{29}$ Additionally, the excess fat acts as a continuous stimulus for chronic, lowgrade systemic inflammation contributing to an increase in 
pulmonary inflammation associated with asthma. ${ }^{29}$ In a largescale study of about 18,000 U.S. children, it has been shown that higher asthma prevalence was associated in children with BMI in the obese and morbidly obese range, whereas no difference was found between overweight and normal weight children. ${ }^{30}$ It is clear that MSHS children comprise a high-risk population for both obesity and asthma and both of these diseases should be addressed together to reduce the health disparities in this population.

In our study, children's age was positively associated with an increased risk of asthma. The association between age and asthma is not clear, and few research studies have been dedicated toward this field. Genetics may play a role, and it is possible that children between the age of 3 and 4 years are increasingly active, which may make asthma symptoms more noticeable by their parents and caretakers, leading them to seek help from health professionals. Furthermore, it is possible that a longer period of exposure to stimulants will make the children more susceptible to developing asthma. However, more research is needed in this area.

Several indicators of socioeconomic status of the study subjects were associated with asthma in this study. Lacking health insurance was associated with increased odds of asthma. In a study by Lara et al, ${ }^{31}$ it was found that compared with other racial/ethnic groups, Mexican children were most likely to have parents with education level below high school, to lack health insurance, and to lack a source of sick care. MSFW's children and families move frequently between different states, and this can become an obstacle to obtain health insurance at their current location, making them more susceptible to poor asthma management and increased risk of asthma exacerbations. ${ }^{13}$

Children whose mothers were unemployed had a higher risk of asthma compared with children whose mothers were employed. Employment status of parents may be closely linked to poverty, household income, and quality of life in general. In a study led by Hillemeier et $a l,{ }^{5}$ children aged 0 to 5 years with asthma had higher poverty rates in addition to other factors. In a recent study, an association was found between a 1-unit reduction in the household income to poverty ratio and $7 \%$ increase in the odds of asthma prevalence, even after adjusting for various sociodemographic factors. $^{32}$ However, it must be noted that no significant association was found between total annual household income and the prevalence of asthma in this study, whereas household income from agricultural work was positively associated with asthma prevalence (data not shown). Increased income from agricultural work may imply that the families are solely dependent on agriculture for their income and lack the opportunity to earn from other nonagricultural means. Nonagricultural work includes any additional labor that is not associated with working in the field with crops or livestock. ${ }^{33}$ Therefore, families are more exposed to agriculture fields and thus components of the field that can stimulate/initiate asthma development (e.g., pesticides, pollens, and other components). These families usually have their young children in the field with them, which increases their risk of exposure to chemicals.
This study reported that the number of people living in households was not associated with asthma treatment. Households with a higher number of children or people may be presumed to have a crowded household. The associations observed from this study population were not consistent with the hygiene hypothesis, which suggests that larger family size and overcrowding are associated with a lower prevalence of asthma. ${ }^{34}$ This might be explained by very unique characteristics of this study population, which predispose them to poorer health status than other populations who have similar socioeconomic status or ethnicity. In the future, this association should be investigated in a larger study group.

According to review studies, genetic factors, environmental tobacco smoke, and family history of asthma were also key risk factors for childhood asthma, although these factors were not addressed in this study. ${ }^{7,8} \mathrm{~A}$ meta-analysis reported that children who had mothers with asthma showed approximately three times higher risk of asthma than those who had mothers without asthma. ${ }^{35}$ Furthermore, environmental tobacco smoke is known to worsen asthma symptoms as well as severe asthma. $^{36}$

This study has several limitations. Due to the cross-sectional design of this study, we could not draw conclusions on causal relationships between several risk factors and asthma. As our dataset did not have the information on key known risk factors such as family history, genetic factors, and household smoking status, we could not examine the association of these risk factors with asthma treatment in this study population. The actual prevalence of asthma may be underestimated in our study as we had to solely rely on parental report of their children's asthma treatments. Since the collected data refers only to Michigan, findings from this study may not be applicable to the entire population of MSFW families throughout other U.S. states. Despite these limitations, our study is unique because this is the first study to examine the prevalence of asthma and its determinants among children from MSFW families who are hard to reach for research and education. Although not very large, our study population was quite substantial for this hard-to-reach community. Our study is critical for preventing asthma among MSFW's children in order to reduce the high prevalence of respiratory illnesses in adulthood and to reduce health care associated costs.

\section{Conclusions}

The study presented here indicates that Michigan MSHS children have a higher prevalence of asthma and obesity compared with the U.S. and Hispanic children of similar age. Children's obesity status and several sociodemographic characteristics of mothers and households were associated with increased prevalence of asthma in the MSHS children. Findings on determinants of asthma in this study might be helpful to design health policies and programs as well as implement health services for this specific population. Future studies with larger sizes and longitudinal data should be directed toward determining additional social and health determinants of asthma among MSFW's children and family members throughout the United States. 


\section{Conflict of Interest}

None declared.

\section{Funding}

This study was partially supported by Michigan Telamon Corporation and the National Institutes of Health (NIHNHLBI grant award 5 R25 HL108864).

\section{Acknowledgments}

The authors thank the Michigan Telamon Corporation for providing the 2012 to 2013 ChildPlus Dataset and also thank the members of the Food and Nutrition Database Research Center in the Department of Food Science and Human Nutrition at Michigan State University for their constructive criticisms on drafts of this manuscript.

\section{References}

1 Malveaux FJ. The state of childhood asthma: introduction. Pediatrics 2009;123(Suppl 3):S129-S130

2 Mirabelli MC, Hsu J, Gower WA. Comorbidities of asthma in U.S. children. Respir Med 2016;116:34-40

3 National Center for Environmental Health. Current Asthma Prevalence Percents by Age, United States: National Health Interview Survey, 2014. Atlanta, GA: Centers for Disease Control and Prevention; 2016

4 National Center for Environmental Health. Asthma's Impact on the Nation: Data from the CDC National Asthma Control Program. Atlanta, GA: Centers for Disease Control and Prevention; 2015

5 Hillemeier MM, Landale NS, Oropesa RS. Asthma in US Mexicanorigin children in early childhood: differences in risk and protective factors by parental nativity. Acad Pediatr 2015;15(04):421-429

6 American Lung Association. Asthma Risk Factors. Available at: http://www.lung.org/lung-health-and-diseases/lung-diseaselookup/asthma/asthma-symptoms-causes-risk-factors/asthmarisk-factors.html. Accessed July 10, 2016

7 Subbarao P, Mandhane PJ, Sears MR. Asthma: epidemiology, etiology and risk factors. CMAJ 2009;181(09):E181-E190

8 Castro-Rodriguez JA, Forno E, Rodriguez-Martinez CE, Celedón JC. Risk and protective factors for childhood asthma: what is the evidence? J Allergy Clin Immunol Pract 2016;4(06):1111-1122

9 Akinbami LJ, Rhodes JC, Lara M. Racial and ethnic differences in asthma diagnosis among children who wheeze. Pediatrics 2005; 115(05):1254-1260

10 Grineski SE, Collins TW, Chavez-Payan P, et al. Social disparities in children's respiratory health in El Paso, Texas. Int J Environ Res Public Health 2014;11(03):2941-2957

11 Crocker D, Brown C, Moolenaar R, et al. Racial and ethnic disparities in asthma medication usage and health-care utilization: data from the National Asthma Survey. Chest 2009;136(04): 1063-1071

12 Al-Shawwa B, Al-Huniti N, Titus G, Abu-Hasan M. Hypercholesterolemia is a potential risk factor for asthma. J Asthma 2006;43 (03):231-233

13 Flores G, Fuentes-Afflick E, Barbot O, et al. The health of Latino children: urgent priorities, unanswered questions, and a research agenda. JAMA 2002;288(01):82-90

14 Perez MK, Piedimonte G. Metabolic asthma: is there a link between obesity, diabetes, and asthma? Immunol Allergy Clin North Am 2014;34(04):777-784

15 Song WO, Song S, Gonzalez A, Shin D, Nieves V. Parents' BMI and weight perception are associated with overweight and obesity among children in Michigan migrant and seasonal farm worker families. J J Commun Med 2015;1:3

16 Kearney GD, Chatterjee AB, Talton J, et al. The association of respiratory symptoms and indoor housing conditions among migrant farmworkers in eastern North Carolina. J Agromed 2014; 19(04):395-405

17 Emmi KE, Jurkowski JM, Codru N, Bell EM, Kacica MA, Carter TP. Assessing the health of migrant and seasonal farmworkers in New York State: statewide data 2003-2005. J Health Care Poor Underserved 2010;21(02):448-463

18 Shore SA, Johnston RA. Obesity and asthma. Pharmacol Ther 2006;110(01):83-102

19 Braveman P, Barclay C. Health disparities beginning in childhood: a life-course perspective. Pediatrics 2009;124(Suppl 3):S163-S175

20 Telamon Corporation. Michigan Migrant Head Start Locations. Available at: http://www.telamon.org/michigan-migrant-headstart.aspx. Accessed July 10, 2016

21 Grummer-Strawn LM, Reinold C, Krebs NF; Centers for Disease Control and Prevention (CDC). Use of World Health Organization and CDC growth charts for children aged 0-59 months in the United States. MMWR Recomm Rep 2010;59(RR-9):1-15

22 Michigan Civil Rights Commission. A Report on the Conditions of Migrant and Seasonal Farmworkers in Michigan. Detroit, MI: Michigan Department of Civil Rights; 2010

23 National Center for Health Statistics. National Health Interview Survey (NHIS): Asthma Content. Atlanta, GA: Centers for Disease Control and Prevention; 2015

24 Centers for Diseases Control and Prevention. Asthma Survey Questions. Available at: https://www.cdc.gov/asthma/questions. htm. Accessed July 10, 2016

25 Ogden CL, Carroll MD, Lawman HG, et al. Trends in obesity prevalence among children and adolescents in the United States, 1988-1994 through 2013-2014. JAMA 2016;315(21):2292-2299

26 Brisbon N, Plumb J, Brawer R, Paxman D. The asthma and obesity epidemics: the role played by the built environment-a public health perspective. J Allergy Clin Immunol 2005;115(05):1024-1028

27 Carroll CL, Stoltz P, Raykov N, Smith SR, Zucker AR. Childhood overweight increases hospital admission rates for asthma. Pediatrics 2007;120(04):734-740

28 Lucas SR, Platts-Mills TA. Paediatric asthma and obesity. Paediatr Respir Rev 2006;7(04):233-238

29 Jensen ME, Collins CE, Gibson PG, Wood LG. The obesity phenotype in children with asthma. Paediatr Respir Rev 2011;12(03):152-159

30 Cottrell L, Neal WA, Ice C, Perez MK, Piedimonte G. Metabolic abnormalities in children with asthma. Am J Respir Crit Care Med 2011;183(04):441-448

31 Lara M, Akinbami L, Flores G, Morgenstern H. Heterogeneity of childhood asthma among Hispanic children: Puerto Rican children bear a disproportionate burden. Pediatrics 2006;117(01):43-53

32 Keet CA, McCormack MC, Pollack CE, Peng RD, McGowan E, Matsui EC. Neighborhood poverty, urban residence, race/ethnicity, and asthma: rethinking the inner-city asthma epidemic. J Allergy Clin Immunol 2015;135(03):655-662

33 US Bureau of Labor Statistics. Occupational Outlook Handbook: Agricultural Workers. Available at: https://www.bls.gov/ooh/farming-fishing-and-forestry/agricultural-workers.htm. Accessed July 10, 2016

34 Brooks C, Pearce N, Douwes J. The hygiene hypothesis in allergy and asthma: an update. Curr Opin Allergy Clin Immunol 2013;13 (01):70-77

35 Lim RH, Kobzik L, Dahl M. Risk for asthma in offspring of asthmatic mothers versus fathers: a meta-analysis. PLoS One 2010;5(04):e10134

36 James AL, Palmer LJ, Kicic E, et al. Decline in lung function in the Busselton Health Study: the effects of asthma and cigarette smoking. Am J Respir Crit Care Med 2005;171(02):109-114 